\title{
Reduced Sleep in the Week Prior to Diagnosis of COVID-19 is Associated with the Severity of COVID-19
}

\author{
Baozhen Huang' \\ Yanlin Niu (D) ${ }^{2}$ \\ Weiguo Zhao ${ }^{3}$ \\ Pengtao $\mathrm{Bao}^{4}$ \\ Diangeng $\mathrm{Li}$ (D) $^{1,5}$
}

'Nanlou Respiratory Diseases Department, 2nd Medical Center of Chinese PLA General Hospital, Beijing, People's Republic of China; ${ }^{2}$ Beijing Center for Disease Prevention and Control, Institute for Nutrition and Food Hygiene, Beijing, People's Republic of China; ${ }^{3}$ Department of Respiratory Medicine, The Eighth Medical Center of Chinese PLA General Hospital, Beijing, People's Republic of China; ${ }^{4}$ Department of Pulmonary and Critical Care Medicine, The Eighth Medical Center of Chinese, Beijing, People's Republic of China; ${ }^{5}$ Department of Nephrology, Chinese PLA General Hospital, State Key Laboratory of Kidney Diseases, National Clinical Research Center for Kidney Diseases, Beijing, People's Republic of China
This article was published in the following Dove Press journal: Nature and Science of Sleep

Background: The rapid outbreak of coronavirus disease 2019 (COVID-19) is a major health concern, in response to which widespread risk factor research is being carried out.

Objective: To discover how physical activity and lifestyle affect the epidemic as well as the disease severity and prognosis of COVID-19 patients.

Methods: This multicenter, retrospective cohort study included 203 adults infected with COVID-19 and 228 uninfected adults in three Chinese provinces, with $164(80.7 \%)$ of the infected participants and $188(82.5 \%)$ of the uninfected participants answering a doctoradministered telephone questionnaire on lifestyle. The binary logistic regression model and the ordinal logit model were used to observe relevance.

Results: Comparing sick and non-sick patients, we found that irregular exercise $(P=0.004)$, sedentary lifestyle $(P=0.010)$, and overexertion $(P<0.001)$ may be associated with the susceptibility to COVID-19. In symptomatic patients, using the recommended status as a reference, risk of severe infection increased with decreased sleep status, being 6.729 (95\% CI $=2.138-21.181)$ times higher for potentially appropriate sleep $(P=0.001)$ and peaking at $8.612(95 \% \mathrm{CI}=1.913-38.760)$ times higher for lack of sleep $(P=0.005)$. Reduction in average daily sleep time significantly increased the likely severity $(P=0.002)$.

Discussion: Through further examination of damage of external lung organs, we found that lack of sleep affected not only disease severity but also prognosis. Based on these findings, the public should prioritize a healthy lifestyle and get adequate sleep in response to the outbreak. The study of life habits may bring new ideas for the prevention and treatment of COVID-19.

Keywords: COVID-19, disease severity, sleep status, damage of external lung organs

\section{Introduction}

The coronavirus disease 2019 (COVID-19) outbreak has caused more than a million infections worldwide. ${ }^{1}$ As research into this disease has intensified, increasing numbers of studies have explored the factors affecting patients' clinical outcomes. Based on Wuhan's experience, older age, duration of fever, and comorbidity were risk factors for disease progression. ${ }^{2-5}$ Some studies have also shown, though not conclusively, that differences in COVID-19 prevalence and severity are associated with smoking. ${ }^{6,7}$ Individuals' physical activity level influences their risk of infection, most likely by affecting immune function. ${ }^{8}$ An animal model test has confirmed that moderate exercise could improve the model animals' ability to resist certain viruses. ${ }^{9,10}$ Moreover, sleep deprivation can increase susceptibility to viral, bacterial, and parasitic infections. ${ }^{11}$
Correspondence: Diangeng $\mathrm{Li}$

Respiratory Diseases

Department, 2nd Medical Center of

Fuxing Road, Beijing 100853, People's

Republic of China

Email lidiangeng@।26.com

Pengtao Bao

Department of Pulmonary and Critical

Care Medicine, The Eighth Medical

Center of Chinese PLA General Hospital,

17th Heishanhu Road, Beijing 100093.

People's Republic of China

Email bao03@I63.com $f$ in $t$ 
Research into COVID-19 and lifestyle has been lacking, despite the potential for discovering influencing factors. Accordingly, we conducted a multicenter retrospective study of 228 uninfected adults and 203 adults who had recovered from SARS-CoV-2 infection in four hospitals in Henan, Shandong, and Hubei provinces to identify correlations of physical activity, exercise habits, sleep, and sedentary lifestyle with disease severity.

\section{Methods}

\section{Participants and Data Collection}

Criteria for inclusion were a history of SARS-CoV-2 infection confirmed by high-throughput sequencing or positive real-time reverse-transcription polymerase-chain-reaction (RT-PCR) assay findings for nasal and pharyngeal swab specimens, ${ }^{12}$ Chinese race, and age $\geq 18$ years at the time of infection. Patients who had severe communication problems (eg, deafness, dementia, mental retardation) were excluded. A total of 203 infected adults, discharged between February 10, 2020, and March 28, 2020, from four clinical centers in three provinces, were admitted to the study cohort. Of these, 164 (80.7\%) answered the doctor's follow-up call and completed the questionnaire (Supplementary Material 1), 23 of whom (14.0\%) were asymptomatic. Participants' personal information (including age, gender, weight, height, and lifestyle) and clinical data (including clinical symptoms and signs, treatment, comorbidities, and laboratory findings from admission to discharge) were reviewed and extracted by the doctors in charge of the patients. Manifestations on computed tomography (CT) were summarized by integrating documentation or description in medical charts and, if available, by further review on the part of our medical staff. Patients reported Borg dyspnea scale (BDS) scores at the time of admission and discharge. Commonly used to measure dyspnea, this self-administered unidimensional assessment tool analyzes breathlessness under exertion (Supplementary Material 2). ${ }^{13}$ Items on exercise habits, physical activity, and sleep were answered by patients in the doctor's telephone follow-up; all such calls were recorded and saved. In total, 228 uninfected adults in the same area were invited to do a telephone interview, of whom 188 (82.5\%) completed the doctor's telephone questionnaire on lifestyle.

\section{Definition of the Variables}

The primary outcome was the severity of COVID-19 patients' infection, categorized by symptoms and clinical indicators with reference to the Diagnosis and Treatment
Plan for COVID-19 (Trial Version 6). ${ }^{14}$ The variable "Damage of external lung organs" was a prognostic index filled in by the doctor according to the patient's other organ damage during hospitalization, based on imaging support, biochemical examination, and the like. The definitions of smoking history and basic disease history were consistent with previous research. ${ }^{15}$ BMI>23.9 was defined as overweight. Exercise habits were defined as exercise activities meeting the National Heart Association's definition weekly in daily activities before COVID-19 diagnosis, including aerobic, anaerobic, and flexibility training, but excluding activities at the intensity of ordinary walking and fishing. ${ }^{16}$ Regular exercise was defined as three or more times a week, for no less than 30 minutes apiece. This study used the International Physical Activity Questionnaire-Short Form to identify physical activity, sleep, and sedentary lifestyle in those infected with COVID-19. ${ }^{17}$ Physical activity was calculated in MET minutes per week: MET value (walking $=3.3$, moderate activity $=4$, vigorous activity $=8$ ) times the minutes the activity was carried out times the number of days the activity was undertaken, with total MET minutes of physical activity a week equaling the sum of walking, moderate activity, and vigorous activity. Activities lasting longer than 3 hours were truncated. Physical activity intensity was divided into three categories: high, medium, and low, according to the standards set by the IPAQ committee. ${ }^{18}$ A sedentary lifestyle was defined as usually sitting for 9 hours or more per day on working days. ${ }^{19}$ Sleep time data took the form of a numerical variable, expressed in hours. A categorical variable, "Sleep status," was also used, according to NSF guidelines: a) recommended; b) may be appropriate; c) lack of sleep. ${ }^{20}$ (No cases of excessive sleep were seen in our cohort.)

\section{Statistics}

Quantitative data were presented as means with standard deviations. If data were not normally distributed, variables were described by median and interquartile range (IQR). Categorical data were presented as percentages of the population in groups. Simple univariate logistic regressions predicted the risk of clinical severity and damage of external lung organs of patients who had COVID-19. Variables that univariate analyses yielded $P$-values $<0.10$, and other special interest variables were included in the multivariable logistic regression model. The ordinal logit model was used to estimate odds ratios (ORs) and 95\% confidence intervals (CIs) for the outcome of clinical severity. The binary logistic regression model was used 
to estimate OR and $95 \% \mathrm{CI}$ for the outcome of damage of external lung organs. For these multivariable models, all ORs having $P$-values $<0.05$ were considered statistically significant. Data were analyzed using SAS 9.2 (SAS Inc., Cary, NC, USA).

\section{Results}

\section{Clinical Data and Lifestyle Between Different Severity Groups}

Among all recorded cases of COVID-19 infection, the proportion of men and women is the same. Among the different severities of symptomatic patients, persons aged 40-59 were the most populous, as shown in Table 1. Among asymptomatic persons, $60.87 \%$ smoked - a figure perhaps skewed by the small number of people enrolled. Overall, about $29.27 \%$ of participants had at least one underlying disease, most commonly hypertension and diabetes-much as in previous research. ${ }^{3,4}$ Among symptomatic patients, the length of hospitalization increased with disease severity, with average hospitalization length for severe patients reaching $22.87 \pm 5.62$ days. Overall, few patients were admitted to the intensive care unit (ICU) and put on ventilators. However, these two circumstances were relatively common among severe patients, at 39.13\% and $60.87 \%$, respectively. Judging from laboratory testing results at the time of admission, severely ill patients generally had more inflammatory reactions, a lower proportion of lymphocytes, and a lower platelet count than mild and normal patients. Up to $47.83 \%$ of asymptomatic patients did not show any signs of lung damage in CT results. Among symptomatic patients, most CT results suggested signs of infection in both lungs. On admission, critically ill patients had higher (3.04 \pm 2.20$)$ BDS scores, consistent with the clinically observed degree of dyspnea in COVID-19 patients. The survey on lifestyle habits before illness focused mainly on 1) the patient's prior exercise habits, 2) whether such habits qualified as regular exercise, 3) physical activity of different intensities, 4) sedentary lifestyle, and 5) average daily sleep time. We describe the relationship between these activity habits and illness hereafter.

\section{Lifestyle Habits' Potential Effect on the Probability of Getting COVID-19}

Owing to the lack of isolation measures taken in its early stages, COVID-19 has spread across the country. We examined the patient group's lifestyles and the non-patient group in the area where the patient group is located, investigating whether the identified lifestyle-related factors affected the probability of contracting disease. Gender, age, BMI, smoking history, underlying disease, exercise habits, sedentary status, physical activity, and sleep status were incorporated into a univariate regression model to explore the factors influencing infection with COVID-19; see Supplementary Table 1 for details. Variables whose univariate analyses yielded $P$-values $<0.10$ are included in the multivariable logistic regression model in Table 2. Considering the possibility of collinearity, only sleep time, rather than sleep status, was included in the multiple regression model. Smoking history $(P=0.001)$, presence of underlying disease $(P<0.001)$, irregular exercise $(P=0.004)$, sedentary lifestyle $(P=0.010)$, and overexertion $(P<0.001)$ were identified as independent risk factors for getting the disease. Irregular exercise can increase illness risk by 2.929 -times (95\% $\mathrm{CI}=1.425-6.022$ ), and a sedentary lifestyle can increase it by 19.168-times (95\% CI=2.044-179.792). Among nonsick participants, we found few sedentary people. Moderate-intensity physical activity was more protective against COVID-19 than high-intensity physical activity $(P<0.001)$. Even relatively low physical activity levels were slightly better than high-intensity physical activity $(P<0.001, \mathrm{OR}=0.069 ; 95 \% \mathrm{CI}=0.026-0.186)$, which may reduce immunity and increase susceptibility to the virus.

\section{Worse Sleep Status Was Associated with the Severity of COVID-19}

The more severe the infection, the greater the probability of the patient's admission to the ICU, and the greater the risk of death. ${ }^{4}$ The severity of infection is a generally emphasized indicator of outcome. Although affecting the patients themselves, it has increased the medical social load. We performed a risk factor analysis of symptomatic patients' severity of infection. In our univariate logistic regression analysis of disease severity, as shown in Supplementary Table 2, smoking history $(P=0.044)$, one kind of underlying disease ( 0 as the reference, $P=0.074)$, exercise habits $(P=0.091)$, both potentially appropriate sleep and lack of sleep (recommended as the reference, $P=0.001$ and $P=0.008)$, average daily sleep time $(P=0.002)$, and low MET intensity classification (high as the reference, $P=0.061)$ were significant $(P<0.1)$ and were used in multiple logistic regression models.

The results, shown in Table 3, reflect two models of multiple logistic regression employing different 
Table I Comparison Between Asymptomatic and Symptomatic Groups

\begin{tabular}{|c|c|c|c|c|c|}
\hline \multirow[t]{2}{*}{ Variables } & \multirow[t]{2}{*}{ Categories } & \multirow{2}{*}{$\begin{array}{l}\text { Asymptomatic } \\
\mathrm{n}(\%) / \text { Mean } \pm \text { SD/Median } \\
(\text { IQR) }\end{array}$} & Mild & Normal & Severe \\
\hline & & & \multicolumn{3}{|c|}{ n (\%)/Mean \pm SD/Median (IQR) } \\
\hline \multirow[t]{2}{*}{ Gender } & Male & $13(56.52 \%)$ & $4(66.67 \%)$ & 56 (50.00\%) & 9 (39.13\%) \\
\hline & Female & $10(43.48 \%)$ & $2(33.33 \%)$ & $56(50.00 \%)$ & $14(60.87 \%)$ \\
\hline Age (years) & & $42.70 \pm 15.25$ & $39.50 \pm 14.40$ & $42.88 \pm 13.90$ & $52.09 \pm 15.23$ \\
\hline \multirow[t]{3}{*}{ Age group } & $20-39$ & $12(52.17 \%)$ & $3(50.00 \%)$ & $50(44.64 \%)$ & $3(13.04 \%)$ \\
\hline & $40-59$ & $8(34.78 \%)$ & $2(33.33 \%)$ & 49 (43.75\%) & $13(56.52 \%)$ \\
\hline & $60-79$ & $3(13.04 \%)$ & I (I6.67\%) & $13(11.61 \%)$ & 7 (30.43\%) \\
\hline \multirow[t]{2}{*}{ BMI Classification } & Normal & $15(65.22 \%)$ & $3(50.00 \%)$ & $67(60.36 \%)$ & $13(56.52 \%)$ \\
\hline & Overweight & $8(34.78 \%)$ & $3(50.00 \%)$ & 44 (39.64\%) & $10(43.48 \%)$ \\
\hline \multirow[t]{2}{*}{ Smoke History } & No & 9 (39.13\%) & $2(33.33 \%)$ & $74(66.67 \%)$ & $19(82.61 \%)$ \\
\hline & Yes & $14(60.87 \%)$ & $4(66.67 \%)$ & 37 (33.33\%) & 4 (17.39\%) \\
\hline \multirow[t]{2}{*}{ Underlying Disease } & No & $18(78.26 \%)$ & $4(66.67 \%)$ & $83(74.11 \%)$ & II (47.83\%) \\
\hline & Yes & $5(21.74 \%)$ & $2(33.33 \%)$ & 29 (25.89\%) & $12(52.17 \%)$ \\
\hline \multirow[t]{2}{*}{ Hypertension } & Yes & $3(13.04 \%)$ & $2(33.33 \%)$ & II (9.82\%) & $6(26.09 \%)$ \\
\hline & No & $20(86.96 \%)$ & $4(66.67 \%)$ & $101(90.18 \%)$ & 17 (73.91\%) \\
\hline \multirow[t]{2}{*}{ Diabetes } & No & 21 (91.30\%) & $5(83.33 \%)$ & 105 (93.75\%) & $19(82.61 \%)$ \\
\hline & Yes & $2(8.70 \%)$ & I (I6.67\%) & 7 (6.25\%) & $4(17.39 \%)$ \\
\hline \multirow[t]{2}{*}{ Cancer } & No & $23(100.00 \%)$ & $6(100.00 \%)$ & 110 (98.21\%) & $23(100.00 \%)$ \\
\hline & Yes & $0(0.00 \%)$ & $0(0.00 \%)$ & $2(1.79 \%)$ & $0(0.00 \%)$ \\
\hline Hospital Stay (days) & & $13.39 \pm 3.79$ & $11.00 \pm 7.43$ & $15.75 \pm 4.64$ & $22.87 \pm 5.62$ \\
\hline \multirow[t]{2}{*}{ In Intensive Care } & No & $23(100.00 \%)$ & $6(100.00 \%)$ & 110 (99.10\%) & $14(60.87 \%)$ \\
\hline & Yes & $0(0.00 \%)$ & $0(0.00 \%)$ & I (0.90\%) & $9(39.13 \%)$ \\
\hline \multirow[t]{2}{*}{ Ventilator } & No & $23(100.00 \%)$ & $6(100.00 \%)$ & 108 (97.30\%) & 9 (39.13\%) \\
\hline & Yes & $0(0.00 \%)$ & $0(0.00 \%)$ & $3(2.70 \%)$ & $14(60.87 \%)$ \\
\hline \multirow[t]{2}{*}{ Damage of external lung organs } & No & $23(100.00 \%)$ & 5 (83.33\%) & 104 (92.86\%) & 7 (30.43\%) \\
\hline & Yes & $0(0.00 \%)$ & I (I6.67\%) & $8(7.14 \%)$ & $16(69.57 \%)$ \\
\hline $\mathrm{Hb}(\mathrm{g} / \mathrm{L})$ & & $131.22 \pm 16.82$ & $139.17 \pm 7.94$ & $131.36 \pm 15.69$ & $128.78 \pm 15.50$ \\
\hline $\operatorname{PLT}\left(10^{\wedge} 9 / \mathrm{L}\right)$ & & $216.65 \pm 85.98$ & $220.33 \pm 51.69$ & $210.52 \pm 79.19$ & $171.13 \pm 59.32$ \\
\hline WBC( $\left(10^{\wedge} 9 / L\right)$ & & $6.55 \pm 1.76$ & $7.60 \pm 3.58$ & $5.34 \pm 2.09$ & $4.59 \pm 2.10$ \\
\hline LYM\% & & $30.75 \pm 11.38$ & $27.12 \pm 18.84$ & $26.17 \pm 11.33$ & $22.20 \pm 11.40$ \\
\hline WBC\% & & $59.17 \pm 10.83$ & $63.67 \pm 18.87$ & $65.43 \pm 13.25$ & $70.12 \pm 12.02$ \\
\hline CRP (mg/L) & & $1.72 \pm 1.60$ & $23.73 \pm 18.69$ & $|6.52 \pm 21.5|$ & $33.57 \pm 32.36$ \\
\hline $\mathrm{PCT}(\mathrm{ng} / \mathrm{mL})$ & & $0.12 \pm 0.09$ & $0.29 \pm 0.37$ & $0.11 \pm 0.14$ & $0.17 \pm 0.21$ \\
\hline \multirow{3}{*}{$\begin{array}{l}\text { Chest-CT Confirmed Lung Damage } \\
\text { Status }\end{array}$} & No sign & II (47.83\%) & $0(0.00 \%)$ & I (0.89\%) & $0(0.00 \%)$ \\
\hline & Single lung & 6 (26.09\%) & I (I6.67\%) & 20 (17.86\%) & I (4.35\%) \\
\hline & Double lungs & 6 (26.09\%) & $5(83.33 \%)$ & 91 (81.25\%) & 22 (95.65\%) \\
\hline $\begin{array}{l}\text { Borg Dyspnea Scale Scores at } \\
\text { Admission }\end{array}$ & & $0.00 \pm 0.00$ & $1.83 \pm 1.44$ & $1.42 \pm 1.70$ & $3.04 \pm 2.20$ \\
\hline \multirow[t]{2}{*}{ Exercise Habit } & Yes & 9 (39.13\%) & $4(66.67 \%)$ & 54 (48.2।\%) & 7 (30.43\%) \\
\hline & No & $14(60.87 \%)$ & $2(33.33 \%)$ & 58 (51.79\%) & 16 (69.57\%) \\
\hline
\end{tabular}

(Continued) 
Table I (Continued).

\begin{tabular}{|c|c|c|c|c|c|}
\hline \multirow[t]{2}{*}{ Variables } & \multirow[t]{2}{*}{ Categories } & \multirow{2}{*}{$\begin{array}{l}\text { Asymptomatic } \\
\text { n (\%)/Mean士SD/Median } \\
\text { (IQR) }\end{array}$} & Mild & Normal & Severe \\
\hline & & & \multicolumn{3}{|c|}{ n (\%)/Mean \pm SD/Median (IQR) } \\
\hline Regular Exercise & $\begin{array}{l}\text { Yes } \\
\text { No }\end{array}$ & $\begin{array}{l}2(8.70 \%) \\
21(91.30 \%)\end{array}$ & $\begin{array}{l}\text { I (16.67\%) } \\
5(83.33 \%)\end{array}$ & $\begin{array}{l}17(15.18 \%) \\
95(84.82 \%)\end{array}$ & $\begin{array}{l}3(13.04 \%) \\
20(86.96 \%)\end{array}$ \\
\hline Total MET*min & & $2835.00(5460.00)$ & $\begin{array}{l}4819.50 \\
(2166.38)\end{array}$ & $\begin{array}{l}4177.50 \\
(2907.00)\end{array}$ & $\begin{array}{l}3532.50 \\
(2673.75)\end{array}$ \\
\hline MET Intensity Classification & $\begin{array}{l}\text { High } \\
\text { Moderate } \\
\text { Low }\end{array}$ & $\begin{array}{l}10(43.48 \%) \\
12(52.17 \%) \\
I(4.35 \%)\end{array}$ & $\begin{array}{l}6(100.00 \%) \\
0(0.00 \%) \\
0(0.00 \%)\end{array}$ & $\begin{array}{l}65(58.56 \%) \\
43(38.74 \%) \\
3(2.70 \%)\end{array}$ & $\begin{array}{l}\text { I4 (63.64\%) } \\
7(31.82 \%) \\
\text { I (4.55\%) }\end{array}$ \\
\hline $\begin{array}{l}\text { Vigorous Activity MET*min } \\
\text { Moderate Activity MET*min } \\
\text { Walking MET*min }\end{array}$ & & $\begin{array}{l}0.00(4800.00) \\
900.00(1680.00) \\
1039.50(1287.00)\end{array}$ & $\begin{array}{l}0.00(840.00) \\
3600.00 \\
(17 \mid 0.00) \\
1386.00 \\
(14 \mid 4.88)\end{array}$ & $\begin{array}{l}0.00(0.00) \\
2520.00 \\
(3400.00) \\
1039.50 \\
(1039.50)\end{array}$ & $\begin{array}{l}0.00(0.00) \\
3120.00 \\
(3240.00) \\
693.00 \\
(1423.13)\end{array}$ \\
\hline Sedentary Population & $\begin{array}{l}\text { No } \\
\text { Yes }\end{array}$ & $\begin{array}{l}23(100.00 \%) \\
0(0.00 \%)\end{array}$ & $\begin{array}{l}6(100.00 \%) \\
0(0.00 \%)\end{array}$ & $\begin{array}{l}106(95.50 \%) \\
5(4.50 \%)\end{array}$ & $\begin{array}{l}22(95.65 \%) \\
\text { I (4.35\%) }\end{array}$ \\
\hline Average daily sleep time $(\mathrm{h})$ & & $6.85 \pm 0.90$ & $7.25 \pm 0.42$ & $7.04 \pm 0.73$ & $6.37 \pm 1.43$ \\
\hline Sleep Status & $\begin{array}{l}\text { Unknown } \\
\text { Recommended } \\
\text { Maybe appropriate } \\
\text { Lack of sleep }\end{array}$ & $\begin{array}{l}0(0.00 \%) \\
I 2(0.00 \%) \\
\text { II }(0.00 \%) \\
0(0.00 \%)\end{array}$ & $\begin{array}{l}0(0.00 \%) \\
6(0.00 \%) \\
0(0.00 \%) \\
0(0.00 \%)\end{array}$ & $\begin{array}{l}\text { I }(0.00 \%) \\
97(0.00 \%) \\
9(0.00 \%) \\
5(0.00 \%)\end{array}$ & $\begin{array}{l}0(0.00 \%) \\
12(0.00 \%) \\
7(0.00 \%) \\
4(0.00 \%)\end{array}$ \\
\hline
\end{tabular}

Notes: Values shown as number (\%) or mean \pm standard deviation or median (Inter Quartile Range). Since all MET*min data are not normally distributed, these variables are described by median and Inter Quartile Range (IQR). BMI Classification, Smoke History, Sedentary Population, Sleep Status missing for one case of symptomatic group.

independent variables of severity outcome. In Model 1, the independent variable representing sleep is categorical sleep status. Taking the recommended status as a reference, risk of severe infection increased with decreased sleep status, reaching $6.729(95 \% \mathrm{CI}=2.138-21.181)$ times higher for potentially appropriate sleep $(P=0.001)$ and peaking at
$8.612(95 \% \mathrm{CI}=1.913-38.760)$ times higher for lack of sleep $(P=0.005)$ in all symptomatic patients. Model 2 used the variable "average daily sleep time (hours)" instead of sleep status, it being believed that reductions in average daily sleep time significantly increase likely severity $(P=0.002)$.

Table 2 Results of Multiple Logistic Regression on Illness

\begin{tabular}{|c|c|c|c|c|c|c|c|}
\hline Items & Categories & DF & Estimate & SE & $\chi^{2}$ & $P$ & OR $(95 \% \mathrm{Cl})$ \\
\hline Intercept & & I & -1.816 & 0.683 & 7.070 & 0.008 & \\
\hline Smoke History (No as reference) & Yes & I & 1.159 & 0.351 & 10.868 & $0.00 I^{*}$ & $3.185(1.600-6.343)$ \\
\hline Underlying Disease (No as reference) & Yes & I & 2.022 & 0.399 & 25.729 & $<0.001 *$ & $7.552(3.458-16.495)$ \\
\hline Regular Exercise (Yes as reference) & No & I & 1.075 & 0.368 & 8.547 & $0.004^{*}$ & $2.929(1.425-6.022)$ \\
\hline Sedentary population (No as reference) & Yes & I & 2.953 & 1.142 & 6.686 & $0.010 *$ & $19.168(2.044-179.792)$ \\
\hline \multirow[t]{2}{*}{ MET Intensity Classification (High as reference) } & Moderate & I & -1.546 & 0.298 & 26.985 & $<0.001 *$ & $0.213(0.119-0.382)$ \\
\hline & Low & I & -2.668 & 0.504 & 28.019 & $<0.001 *$ & $0.069(0.026-0.186)$ \\
\hline
\end{tabular}

Notes: Significant level is 0.05 and significant $P$-values are shown withan asterisk.

Abbreviations: SE, standard error; OR, odds ratio; $P, P$-value of multiple logistic regression. 
Table 3 Models of Multiple Logistic Regression Employing Different Independent Variables of Severity Outcome

\begin{tabular}{|c|c|c|c|c|c|c|c|c|}
\hline Models & Variables & Categories & DF & Estimate & SE & $\chi^{2}$ & $P$ & OR $(95 \% \mathrm{Cl})$ \\
\hline \multirow[t]{4}{*}{ Model I } & \multirow[t]{2}{*}{ Intercept } & Hospital stay $\geq 20$ days & I & -2.143 & 0.305 & 49.277 & $<0.001$ & \\
\hline & & $\begin{array}{l}\text { Hospital stay 10-19 } \\
\text { days }\end{array}$ & I & 3.103 & 0.457 & 46.022 & $<0.001$ & \\
\hline & \multirow[t]{2}{*}{$\begin{array}{l}\text { Sleep status (Recommended as } \\
\text { reference) }\end{array}$} & Maybe appropriate & I & 1.907 & 0.585 & 10.620 & $0.001 *$ & $\begin{array}{l}6.729 \\
(2.138-21.181)\end{array}$ \\
\hline & & Lack of sleep & I & 2.153 & 0.768 & 7.871 & $0.005^{*}$ & $\begin{array}{l}8.612 \\
(1.913-38.760)\end{array}$ \\
\hline \multirow[t]{3}{*}{ Model 2} & \multirow[t]{2}{*}{ Intercept } & Hospital stay $\geq 20$ days & I & 3.621 & 1.643 & 4.859 & 0.028 & \\
\hline & & $\begin{array}{l}\text { Hospital stay } 10-19 \\
\text { days }\end{array}$ & I & 8.773 & 1.834 & 22.889 & $<0.001$ & \\
\hline & Average daily sleep time $(\mathrm{h})$ & & I & -0.771 & 0.243 & 10.041 & $0.002 *$ & $\begin{array}{l}0.463 \\
(0.287-0.745)\end{array}$ \\
\hline
\end{tabular}

Notes: Significant level is 0.05 and significant $P$-values are shown with an asterisk. Model I: took clinical severity as the dependent variable and Sleep status (Categorical variable) as one of independent variables; Model 2: took clinical severity as the dependent variable and Average daily sleep time (hours) as one of the independent variables. Score Test for the Proportional Odds Assumption: Model I: $\chi^{2}=0.1570$, DF=2, $P=0.9245$; Model 2: $\chi^{2}=0.0012, D F=I, P=0.9726$, which suggested that these two models satisfy the assumption.

Abbreviations: SE, standard error; OR, odds ratio; $P, P$-value of multiple logistic regression.

\section{Discussion}

The relationship between sleep and disease severity is particularly important because recent decades have seen a documented decrease in the mean duration of sleep and an increase in shift work even as rich entertainment options and social networking methods have encouraged people to spend less time sleeping. Sleep-deprivation experiments in both animals and humans have provided strong evidence for a crucial role of sleep in the immune response. $^{21}$ In humans, general patterns have emerged, indicating that sleep deprivation has detrimental effects on immune cell number, function, and cytokine production. Furthermore, lack of sleep may promote the release of inflammatory factors and impair human immunity against pathogens. ${ }^{22}$ Experimental sleep restriction studies have shown that sleep duration is associated with alterations in ex vivo measures of cellular immunity that have been implicated in increased risk of contracting infectious disease (eg, natural killer cell activity, T-cell proliferative response). ${ }^{23}$ Large-scale clinical research, including a study of 56,953 female nurses, has shown that both reduced sleep time and prolonged habitual sleep durations are associated with increased risk of pneumonia. ${ }^{24}$ Among US adults, those who have short sleep times are at higher risk of respiratory infections than participants who get $7-8$ hours of sleep nightly. ${ }^{25}$ Our results also show that during the COVID-19 epidemic, people who get insufficient sleep are more likely to have more severe disease. An inverse relationship was seen between average daily sleep time and severity of disease before illness.

To elaborate on the effect of sleep on COVID-19 patients, we also conducted a regression analysis using damage of external lung organs as the outcome. In Table 4, age group (20-39 years as the reference; $40-59$ years, $P=0.006$; and 60-79 years, $P<0.001$ ), the presence of an underlying disease $(P<0.001)$, the presence of $1-3$ kinds of underlying disease $(P<0.1)$, the presence of hypertension $(P<0.1)$, potentially appropriate sleep status (recommended as the reference, $P<0.001$ ), and average daily sleep time were risk factors in the univariate logistic regression model $(P<0.1)$. We found that the presence of underlying diseases and reduced sleep were two significant risk factors through further binary logistic regression, as shown in Table 5. In Model 3, the independent variable representing sleep is categorical sleep status. Model 4 used the variable "average daily sleep time (hours)" instead of sleep status. Having an underlying disease significantly increased the risk $(P=0.002)$, which was $5.150(95 \%$ $\mathrm{CI}=1.801-14.732)$ times that seen with the absence of underlying disease. For patients who had COVID-19, the possibility of developing damage of external lung organs decreased with increases in average daily sleep time $(P<0.001)$. Functional sleep status could improve clinical status and reduce the likelihood of damage of external lung organs, 
Table 4 Results of Univariate Logistic Regression on Damage of External Lung Organs

\begin{tabular}{|c|c|c|c|c|c|c|c|}
\hline Items & Categories & DF & Estimate & SE & $\chi^{2}$ & $P$ & OR $(95 \% \mathrm{Cl})$ \\
\hline Gender (Male as reference) & & 1 & -0.476 & 0.389 & 1.498 & 0.221 & $0.621(0.290-1.332)$ \\
\hline \multirow[t]{2}{*}{ Age Groups (20-39 years as reference) } & 40-59 Years & 1 & 2.140 & 0.771 & 7.711 & $0.006^{*}$ & $8.500(1.877-38.495)$ \\
\hline & $60-79$ Years & 1 & 3.062 & 0.796 & 14.786 & $<0.001 *$ & $21.375(4.488-101.808)$ \\
\hline BMI Classification (Normal as reference) & Overweight & 1 & 0.342 & 0.421 & 0.662 & 0.416 & $1.408(0.617-3.214)$ \\
\hline Smoke History (No as reference) & Yes & 1 & -0.054 & 0.447 & 0.015 & 0.907 & $0.947(0.395-2.273)$ \\
\hline Underlying Disease (No as reference) & Yes & 1 & 1.481 & 0.403 & 13.496 & $<0.001 *$ & $4.397(1.995-9.691)$ \\
\hline \multirow[t]{3}{*}{ Number of Underlying Disease ( 0 as reference) } & 1 & 1 & 1.407 & 0.461 & 9.315 & $0.002 *$ & $4.082(1.654-10.072)$ \\
\hline & 2 & 1 & 1.155 & 0.665 & 3.015 & $0.083^{*}$ & $3.175(0.862-11.693)$ \\
\hline & 3 & 1 & 1.966 & 0.763 & 6.648 & $0.010^{*}$ & $7.143(1.603-31.836)$ \\
\hline Hypertension (No as reference) & Yes & 1 & -0.752 & 0.443 & 2.884 & $0.089^{*}$ & $0.47 \mid(0.198-1.123)$ \\
\hline Diabetes (No as reference) & Yes & 1 & 0.779 & 0.542 & 2.063 & 0.151 & $2.179(0.753-6.304)$ \\
\hline Cancer (No as reference) & Yes & 1 & 1.394 & 1.428 & 0.953 & 0.329 & $4.030(0.246-66.138)$ \\
\hline Exercise Habit (Yes as reference) & No & 1 & 0.506 & 0.456 & 1.231 & 0.267 & $1.659(0.678-4.056)$ \\
\hline Regular Exercise (Yes as reference) & No & 1 & -0.446 & 0.568 & 0.618 & 0.432 & $0.640(0.210-1.948)$ \\
\hline Sedentary population (No as reference) & Yes & 1 & -0.035 & 1.119 & 0.001 & 0.975 & $0.966(0.108-8.656)$ \\
\hline \multirow[t]{2}{*}{ Sleep Status (Recommended as reference) } & May Be Appropriate & 1 & 2.938 & 0.620 & 22.484 & $<0.001 *$ & $18.880(5.605-63.596)$ \\
\hline & Too Low & 1 & 0.897 & 0.858 & 1.094 & 0.296 & $2.452(0.456-13.176)$ \\
\hline \multirow[t]{2}{*}{ MET Intensity Classification (High as reference) } & Moderate & 1 & -0.575 & 0.549 & 1.098 & 0.295 & $0.563(0.192-1.650)$ \\
\hline & Low & 1 & 1.216 & 0.812 & 2.243 & 0.134 & $3.375(0.687-16.582)$ \\
\hline Average daily sleep time $(\mathrm{h})$ & & I & -0.952 & 0.269 & 12.566 & $<0.001 *$ & $0.386(0.228-0.653)$ \\
\hline
\end{tabular}

Notes: Significant level is 0.1 and significant $P$-values are shown with an asterisk.

Abbreviations: $\mathrm{SE}$, standard error; OR, odds ratio; $P, P$-value of univariate logistic regression.

Table 5 Models of Binary Logistic Regression on Damage of External Lung Organs

\begin{tabular}{|c|c|c|c|c|c|c|c|c|}
\hline Models & Variables & Categories & DF & Estimate & $\begin{array}{l}\text { Standard } \\
\text { Error }\end{array}$ & $\chi^{2}$ & $P$ & OR $(95 \% \mathrm{Cl})$ \\
\hline \multirow[t]{6}{*}{ Model 3} & Intercept & & I & -4.639 & 0.962 & 23.239 & $<0.001$ & \\
\hline & \multirow{2}{*}{$\begin{array}{l}\text { Age Groups ( } 20-39 \text { years as } \\
\text { reference) }\end{array}$} & 40-59 Years & 1 & 1.951 & 0.933 & 4.373 & 0.037 & $7.034(1.130-43.782)$ \\
\hline & & 60-79 Years & I & 2.608 & 1.041 & 6.270 & 0.012 & $13.566(1.762-104.444)$ \\
\hline & $\begin{array}{l}\text { Underlying Disease (No as } \\
\text { reference) }\end{array}$ & Yes & I & 1.433 & 0.622 & 5.310 & $0.021 *$ & $4.192(1.239-14.184)$ \\
\hline & \multirow[t]{2}{*}{$\begin{array}{l}\text { Sleep status (Recommended as } \\
\text { reference) }\end{array}$} & $\begin{array}{l}\text { May Be } \\
\text { Appropriate }\end{array}$ & I & 3.427 & 0.792 & 18.746 & $<0.00 I^{*}$ & $30.784(6.525-145.233)$ \\
\hline & & Too Low & I & 1.186 & 1.033 & 1.318 & 0.251 & $3.273(0.432-24.777)$ \\
\hline \multirow[t]{3}{*}{ Model 4} & Intercept & & I & 5.716 & 2.205 & 6.719 & 0.010 & \\
\hline & $\begin{array}{l}\text { Underlying Disease (No as } \\
\text { reference) }\end{array}$ & Yes & I & 1.639 & 0.536 & 9.345 & $0.002^{*}$ & $5.150(1.801-\mid 4.732)$ \\
\hline & Average daily sleep time $(\mathrm{h})$ & & I & -1.186 & 0.333 & $|2.65|$ & $<0.00 I^{*}$ & $0.305(0.159-0.587)$ \\
\hline
\end{tabular}

Notes: Significant level is 0.05 and significant $P$-values are shown with an asterisk. Model 3: took the extrapulmonary organ damage as the dependent variable and sleep status (Categorical variable) as one of the independent variables; Model 4: took the extrapulmonary organ damage as the dependent variable and average daily sleep time (hours) as one of the independent variables.

Abbreviations: SE, standard error; OR, odds ratio; $P, P$-value of $\chi^{2}$ test. 
effects perhaps related to certain immune promotion mechanisms that have not yet been studied clearly.

In the global context of the COVID-19 outbreak, public members should engage in moderate physical activity and get adequate sleep as a response to the outbreak actively. This study and other similar studies have demonstrated that lifestyles are related to the susceptibility and disease severity of COVID-19. We encourage others to investigate the life habits of patients before they are admitted. Through a simple survey of a patient's lifestyle, doctors could make auxiliary judgments about likely future disease severity. However, this study does have certain limitations: It did not include enough people, and the questionnaire was a subjective measure. Accordingly, to increase data accuracy, we included infected people from four medical centers in three Chinese provinces and asked doctors to administer the questionnaire by telephone as much as possible. We also began larger-scale and more in-depth research with which to track and investigate the effect of lifestyle on long-term rehabilitation from COVID-19 to offer suggestions for public response.

\section{Abbreviations}

COVID-19, coronavirus disease 2019; SARS-CoV-2, severe acute respiratory syndrome coronavirus 2; RTPCR, real-time reverse-transcription polymerase-chainreaction; $\mathrm{CT}$, computed tomography; IPAQ, International Physical Activity Questionnaire; NSF, National Sleep Foundation; OR, odds ratio; CI, confidence interval; BMI, body mass index; MET, metabolic equivalent of task.

\section{Ethics Declarations}

The study complied with the Declaration of Helsinki and the ethical approval in this study was obtained from the Research and Ethics Committee of the Chinese PLA General Hospital (No. S2020-063-01). All patients involved in this study signed informed consent.

\section{Acknowledgments}

We appreciated the parents and all the doctors and nurses involved in this study who contributed to the COVID-19 rescue and follow-up research.

\section{Author Contributions}

Baozhen Huang and Yanlin Niu contributed the same in this study. All authors made substantial contributions to the conception and design, acquisition of data, or analysis and interpretation of data; took part in drafting the article or revising it critically for important intellectual content; agreed on the journal to which the article will be submitted; gave final approval of the version to be published; and agree to be accountable for all aspects of the work.

\section{Funding}

This research is supported by the Beijing Municipal Natural Science Foundation (No. 7204308); the National Natural Science Foundation of China (No. 81901404); and partially supported by the Open Project Program of the State Key Laboratory of Kidney Diseases in PLA General Hospital (No. KF2018-06).

\section{Disclosure}

The authors declare that they have no conflict of interest for this work.

\section{References}

1. WHO. Available from: https://www.who.int. Accessed March 31, 2020.

2. Fan T, Hao B, Yang S, et al. Clinical characteristics of COVID-19 and establishment of a disease risk prediction model. SSRN J. 2020. doi: $10.2139 /$ ssrn. 3556660

3. Zhu Q, Zhao S, Lai X, et al. Dose-response association between risk factors and incidence of COVID-19 in 325 hospitalized patients: a Multicenter Retrospective Cohort Study. SSRN J. 2020. doi: $10.2139 /$ ssrn.3562478

4. Zhou F, Yu T, Du R, et al. Clinical course and risk factors for mortality of adult inpatients with COVID-19 in Wuhan, China: a retrospective cohort study. Lancet. 2020;395(10229):1054-1062. doi:10.1016/S0140-6736(20)30566-3

5. Murthy S, Gomersall CD, Fowler RA. Care for critically Ill patients with COVID-19. JAMA. 2020;323(15):1499. doi:10.1001/jama.2020.3633

6. Cai H. Sex difference and smoking predisposition in patients with COVID-19. Lancet Respir Med. 2020;8(4):e20. doi:10.1016/S22132600(20)30117-X

7. Zhao Y, Zhao Z, Wang Y, Zhou Y, Ma Y, Zuo W. Single-cell RNA expression profiling of ACE2, the receptor of SARS-CoV-2. Bioinformatics. 2020. doi:10.1101/2020.01.26.919985

8. Gleeson M, Walsh NP. The BASES expert statement on exercise, immunity, and infection. $J$ Sports Sci. 2012;30(3):321-324. doi:10.1080/02640414.2011.627371

9. Lowder T, Padgett DA, Woods JA. Moderate exercise protects mice from death due to influenza virus. Brain Behav Immun. 2005;19 (5):377-380. doi:10.1016/j.bbi.2005.04.002

10. Martin SA, Pence BD, Woods JA. Exercise and respiratory tract viral infections. Exerc Sport Sci Rev. 2009;37(4):157-164. doi:10.1097/ JES.0b013e3181b7b57b

11. Ilbarra-Coronado EG, Pantaleón-Martínez AMA, VelazquézMoctezuma J, et al. The bidirectional relationship between sleep and immunity against infections. J Immunol Res. 2015;2015:1-14. doi: $10.1155 / 2015 / 678164$

12. Corman VM, Landt O, Kaiser M, et al. Detection of 2019 novel coronavirus (2019-nCoV) by real-time RT-PCR. Eurosurveillance. 2020;25:3. doi:10.2807/1560-7917.ES.2020.25.3.2000045

13. Khair RM, Nwaneri C, Damico RL, Kolb T, Hassoun PM, Mathai SC. The minimal important difference in borg dyspnea score in pulmonary arterial hypertension. Ann Am Thorac Soc. 2016;13(6):842-849. doi:10.1513/AnnalsATS.201512-824OC 
14. Diagnosis and treatment plan for COVID-19 (trial version 6). Chin Med J. 2020.

15. Guan W, Liang W, Zhao Y, et al. Comorbidity and its impact on 1590 patients with COVID-19 in China: a nationwide analysis. Eur Respir J. 2020;55(5):2000547. doi:10.1183/13993003.00547-2020

16. US Department of Health and Human Services, \& National Institutes of Health. Your Guide to Physical Activity and Your Heart (No. 065714). NIH Publication; 2006.

17. Boon RM, Hamlin MJ, Steel GD, Ross JJ. Validation of the New Zealand Physical Activity Questionnaire (NZPAQ-LF) and the International Physical Activity Questionnaire (IPAQ-LF) with accelerometry. Br J Sports Med. 2010;44(10):741-746. doi:10.1136/ bjsm.2008.052167

18. IPAQ committee. Guidelines for data processing and analysis of the International Physical Activity Questionnaire (IPAQ). November, 2005. Available from: http://www.ipaq.ki.se/scoring.html. Accessed September 23, 2020.

19. Scholes S, Bridges S, Ng Fat L, Mindell JS, Brucki S. Comparison of the physical activity and sedentary behaviour assessment questionnaire and the short-form international physical activity questionnaire: an analysis of health survey for England data. Brucki S, ed. PLoS One. 2016;11(3):e0151647. doi:10.1371/journal.pone.0151647
20. National Sleep Foundation. National sleep foundation recommends new sleep times. February 2, 2015. Available from: https://www. sleepfoundation.org/press-release/national-sleep-foundationrecommends-new-sleep-times. Accessed September 23, 2020.

21. Bryant PA, Trinder J, Curtis N. Sick and tired: does sleep have a vital role in the immune system? Nat Rev Immunol. 2004;4(6):457-467. doi:10.1038/nri1369

22. Krueger J. The role of cytokines in sleep regulation. CPD. 2008;14 (32):3408-3416. doi:10.2174/138161208786549281

23. Irwin M, McClintick J, Costlow C, Fortner M, White J, Gillin JC. Partial night sleep deprivation reduces natural killer and cellular immune responses in humans. FASEB J. 1996;10(5):643-653. doi:10.1096/fasebj.10.5.8621064

24. Patel SR, Malhotra A, Gao X, Hu FB, Neuman MI, Fawzi WW. A prospective study of sleep duration and pneumonia risk in women. Sleep. 2012;35(1):97-101. doi:10.5665/sleep.1594

25. Prather AA, Leung CW. Association of insufficient sleep with respiratory infection among adults in the United States. JAMA Intern Med. 2016;176(6):850. doi:10.1001/jamainternmed.2016.0787

\section{Publish your work in this journal}

Nature and Science of Sleep is an international, peer-reviewed, open access journal covering all aspects of sleep science and sleep medicine, including the neurophysiology and functions of sleep, the genetics of sleep, sleep and society, biological rhythms, dreaming, sleep disorders and therapy, and strategies to optimize healthy sleep.
The manuscript management system is completely online and includes a very quick and fair peer-review system, which is all easy to use. Visit http://www.dovepress.com/testimonials.php to read real quotes from published authors. 